\title{
Feline platynosomiasis in Klang Valley, Malaysia: Diagnosis, pathology and management
}

\author{
Nur-Amalina, N. ${ }^{1}$, Watanabe, M. $^{2}$, Mazlina, $M .{ }^{1}$, Che-Amat, A. ${ }^{3}$, Nor-Azlina, A.A. ${ }^{1 *}$ \\ ${ }^{1}$ Department of Veterinary Pathology \& Microbiology, Faculty of Veterinary Medicine, Universiti Putra Malaysia, 43400 UPM Serdang, Malaysia \\ 2Department of Companion Animal Medicine \& Surgery, Faculty of Veterinary Medicine, Universiti Putra Malaysia, 43400 UPM Serdang, Malaysia \\ ${ }^{3}$ Department of Veterinary Clinical Studies, Faculty of Veterinary Medicine, Universiti Putra Malaysia, 43400 UPM Serdang, Malaysia \\ *Corresponding author: azlinaaziz@upm.edu.my
}

\section{ARTICLE HISTORY}

Received: 15 December 2021 Revised: 24 January 2022

Accepted: 24 January 2022

Published: 20 February 2022

\begin{abstract}
Platynosomum fastosum (synonym Platynosomum concinnum, Platynosomum illiciens) is a hepatic fluke causing platynosomiasis or 'lizard poisoning' in cats. This disease is generally being underestimated by veterinary practitioners due to lack of awareness and difficulty in diagnosis although the severe cases of platynosomiasis could be fatal. This study was designed to detect the presence of cat liver fluke through faecal examination among cats kept in shelters, pet cats and stray cats around Klang Valley, Malaysia. The detection of liver flukes among stray cats was based on post-mortem examination. A total of 201 faecal samples were collected from eight shelters $(n=119)$ and five veterinary clinics $(n=82)$ in Klang Valley were subjected to simple floatation and formalin-ether sedimentation techniques for ova detection. P. fastosum ova were identified in three faecal samples obtained from shelters (2.52\%) and three samples collected from veterinary clinics (3.66\%) by faecal examination. A total of 51 stray cats were procured from Pest and Animal Control Unit of the respective municipality. The cats were euthanised and necropsied to collect liver samples and bile duct. The liver was then dissected for isolation and identification of the fluke and bile duct fluid were aspirated for detection of fluke ova. Twelve cats $(23.5 \%)$ were positive for P. fastosum and ova were found in their bile. Macroscopically, affected cats showed mottled liver (33.3\%), distended gall bladder with thick tenacious bile $(66.7 \%)$ that microscopically exhibited hepatic steatosis $(25.0 \%)$ and hepatitis (33.3\%). The severity of parasite load was almost equally distributed between the positive cats with low ( $n=5$, $55.6 \%$; $>125$ adult fluke) and high parasite burden $(n=4,44.4 \% ;<125$ adult fluke) cats, respectively. This study revealed the detection of $P$. fastosum among pet, shelters and stray cats in Klang Valley, Malaysia.
\end{abstract}

Keywords: Platynosomum fastosum; detection; necropsy; cat liver fluke; lizard poisoning.

\section{INTRODUCTION}

Platynosomum fastosum (P. fastosum), also known as Platynosomum concinnum (P. concinnum) and Platynosomum illiciens (P. illiciens), the causal agent of platynosomiasis or lizard poisoning in domestic cats (Felis catus) induces hepatic lesions such as centrolobular congestion, cholangitis and cholestasis (Xavier et al., 2007; Carreira et al., 2008; Andrade et al., 2012). Undoubtedly, the likelihood of $P$. fastosum in cats being mild or asymptomatic (Taylor \& Perri, 1977) poses a challenge for the confirmatory diagnosis of the disease.

Through experimental studies, land snails (Subulina octona and Eulota similaris) are believed to be the first intermediate host while isopods (Oniscidea) as the second intermediate host and lizard serves as the paratenic host (Pinto et al., 2014). Due to feline natural predatory instinct, lizards are implicated in transmitting the infective form known as metacercaria of P. fastosum (Basu \& Charles, 2014).

This ubiquitous presence of this fluke in the tropical and subtropical regions is correlated with the abundance of its intermediate host. In many parts of Asia, P. fastosum had been reported in Indonesia (Warren et al., 1998), Korea (Kim et al., 2010), Malaysia (Retnasabapathy \& Prathap, 1971; AminBabjee, 1978; Shanta et al., 1980; Mohd Zain et al., 2013), Thailand (Jittapalapong et al., 2007) and Vietnam (Le, 2012). The detection of $P$. fastosum in Malaysia were varying from 9.8\% to 75.5\% (Retnasabapathy \& Prathap, 1971; Amin-Babjee, 1978; Shanta et al., 1980; Mohd Zain et al., 2013). Nevertheless, those studies in Malaysia simply reported the detection without assessing the worm burden and associated pathologies.

The infection of liver fluke often causes non-specific clinical effects such as anorexia, lethargy, vomiting, abdominal ascites, hepatomegaly, which might eventually 
lead to the death of the infected cat. Recently, the association of platynosomiasis to the clinical signs including cholangitis was proven to be significant (Lima et al., 2021). However, the significance of platynosomiasis in cats is still controversial due to the high prevalence of mild and asymptomatic forms of the disease (Taylor \& Perri, 1977; Rodriguez-Vivas et al., 2004). This is mainly attributed to the low burden of the parasite in the animal body. Nevertheless, cats with higher burden infections will lead to the damage of the liver cell and thickening of the bile duct; thereby, leading to jaundice and death (Rodriguez-Vivas et al., 2004; Salomao et al., 2005). There are limited studies on platynosomiasis in cats since most of the infections do not cause significant clinical effects. Besides, the majority of accidental discoveries reported that infected cats did not develop any clinical signs related to the Platynosomum spp. infections. Nevertheless, the cat liver fluke infection has been previously reported in a jaundiced cat with dehydration, alopecia, anorexia, prostration, abdominal enlargement and slightly hyperthermic with normal heart and respiratory rate (Ikhwan-Saufi et al., 2020). Lesion-wise, the gross pathology and hepatic injury caused by $P$. fastosum infections are distended gallbladder with fluke infestation, enlarged, fatty, yellow-ish and friable liver, dilated and thickened bile ducts, cholestasis (Vieira et al., 2009), cholangitis, intense periductal fibrosis, periductal inflammatory infiltrate, destruction and loss of bile ducts, severe cholangiohepatitis and obstructive biliary cirrhosis (Soto et al., 1991; Day, 1995; Center, 1996; Headley et al., 2012; Daniel et al., 2012, Ramos et al., 2017).

Currently, cases of platynosomiasis are emerging in veterinary clinics in Malaysia (Nor Azlina Abdul Aziz, personal communication) which marks the need of investigating this endemic disease. Therefore, it is pertinent to conduct further investigation and exploration of $P$. fastosum. Fundamental studies on the prevalence and epidemiology of the cat liver fluke in our country is important in creating awareness of this fatal disease among veterinary practitioners. This study aimed to investigate the presence of cat liver fluke among cats in shelters, pets and strays, to determine if association exists between $P$. fastosum infections with management practices and animal behaviour among pet and shelter cats, as well as to describe the post-mortem changes that occurred due to $P$. fastosum infection in stray cats.

\section{MATERIALS AND METHODS}

\section{Ethics Statement}

The application for animal ethical clearance for this study was approved by the Institutional Animal Care and Use Committee of Universiti Putra Malaysia (IACUC) (AUP No.: UPM/IACUC/AUP-R093/2018). The sample size for this study was based previous study in Malaysia (9.8\%) (Mohd Zain et al., 2013). A consent form was distributed to the pet and shelter owners or representatives prior to the sampling procedure. They were briefed on the nature of the research, and the animals involved will be handled according to the animal ethics law and guidelines set by the IACUC of Universiti Putra Malaysia. The questionnaire regarding cat managements was approved by the Ethics Committee for Research Involving Human Subjects (JKEUPM) with approval number of JKEUPM-2019-035 for distribution to the pet and shelter owners.

\section{Faecal sampling and analysis}

A cross-sectional study was carried out in the central region of Peninsular Malaysia, including the capital city, Kuala
Lumpur $\left(03^{\circ} 07^{\prime} 25.2^{\prime \prime} \mathrm{N} / 101^{\circ} 42^{\prime} 58.2^{\prime \prime} \mathrm{E}\right)$ and the neighbouring state, Selangor $\left(03^{\circ} 00^{\prime} 14.2^{\prime \prime} \mathrm{N}, 101^{\circ} 36^{\prime} 19.6^{\prime \prime}\right.$ E) from March to September 2019.

The faecal sampling was conducted in the Klang Valley area involving eight shelters and five veterinary clinics (Figure 1). A total of 201 faecal samples were collected comprising of 119 samples from shelters and 82 samples from pet cats. Samples from the shelters were obtained in a shared litterbox where the individual cats could not be traced. Each sample obtained from shelter cats were assumed from a single cat. The samples obtained from the clinics were collected from individually-caged cats. Thereafter, the samples were placed in a cooler box during transportation and sent to Parasitology Laboratory, Faculty of Veterinary Medicine, Universiti Putra Malaysia (UPM). The samples were placed in the refrigerator $\left(4^{\circ} \mathrm{C}\right)$ overnight before further analysis.

Two different techniques were used for the identification of fluke ova which are known as the floatation method (Zajac \& Conboy, 2006) and the centrifugal faecal sedimentation test in formal-ether solution (Rocha et al., 2014). Any ova isolated from these samples through faecal analyses was pipetted out in a microcentrifuge tube with normal saline. The samples were stored at $-20^{\circ} \mathrm{C}$ for molecular identification.

\section{Questionnaire on management practices and cat behaviour}

Questionnaire and consent forms were distributed to the owner or the caretaker of the shelters and pet owners prior to the sampling to obtain management and behaviour information of their cats. The questionnaire consists of management enquiry regarding the cat's housing, feeding and deworming status while behaviour mainly on the hunting behaviour. The awareness and knowledge of platynosomiasis were included in the questionnaire.

\section{Post-mortem}

A total of 51 stray cats were procured from the Pest and Animal Control Unit (PACU) of the municipality, which was then transported to the Faculty of Veterinary Medicine, Universiti Putra Malaysia. These cats were euthanised intracardially with $0.5 \mathrm{ml} / \mathrm{kg}$ of pentobarbital sodium following prior sedation with ketamine and acepromazine in accordance with the "AVMA Guidelines for the Euthanasia of Animals: 2020 Edition" (Underwood \& Anthony, 2020).

Before euthanasia, the cats were labelled, weighed and classified by sex and age. The age of the cats was determined using dentition structure (Sutton et al., 2018) while body score condition was assessed using the method described previously (Burkholder, 2000).

For the stray cats collected from the PACU, management information was not included as the animal were to be euthanised after five days if no adoption occurred.

Post-mortem investigation was conducted immediately after euthanasia where samples of liver, bile juice, bile duct, and faeces in the rectum were collected. The whole liver organ was immersed in a water bath $\left(38-40^{\circ} \mathrm{C}\right)$ to allow the activation of flukes. This will aid detection and collection of the flukes. Flukes were collected and preserved in $70 \%$ ethanol for further analysis. The number of flukes collected per sample were recorded to assess the fluke burden for each animal (Braga et al., 2016). The bile juice and faecal samples of each cat were used for ova detection. Any ova isolated through faecal examination and direct smear of bile juice was extracted and stored in a microcentrifuge tube with normal saline at $-20^{\circ} \mathrm{C}$ for further analysis. The flukes were identified based on the morphology characteristic (Bray 


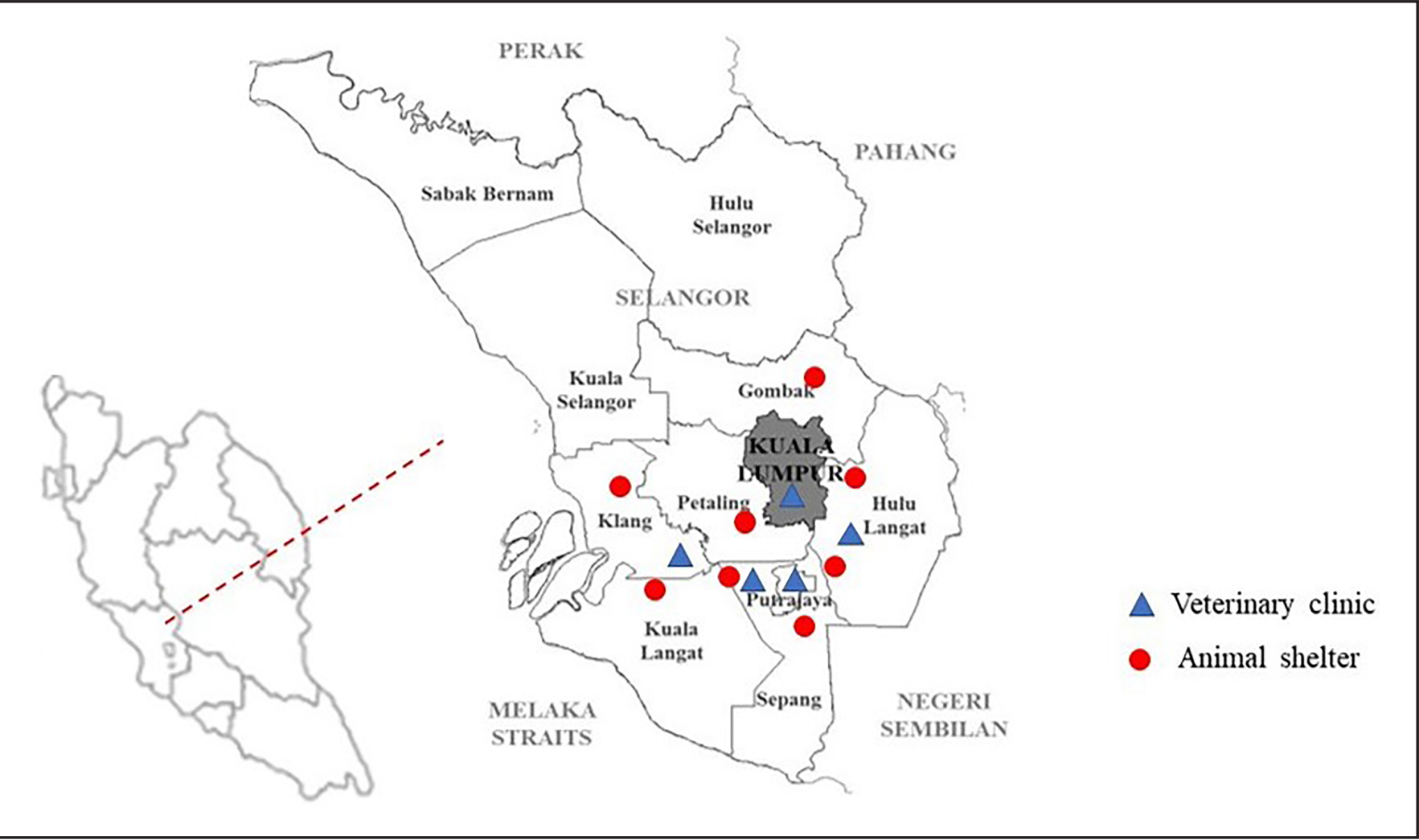

Figure 1. Map of the sampling site around Klang Valley, Malaysia. Animal shelters and veterinary clinics involved are marked with red and blue markings.

et al., 2008). The detection of ova using bile samples was carried out by direct smear method. A drop of bile juice was smeared on a glass slide covered with a cover slip and viewed under a light microscope using 100X magnification. For qualitative analysis, the presence or absence of $P$. fastosum ova in each sample was recorded. The ova were identified based on the morphology characteristics (Palumbo et al., 1976; Montserin et al., 2013).

\section{Histological examination}

Liver tissues from fluke-positive samples were fixed in $10 \%$ formaldehyde and sent for routine histopathology processing and examination at the Histopathology Laboratory, Faculty of Veterinary Medicine, Universiti Putra Malaysia. The samples were stained with hematoxylin and eosin (HE) and examined under a compound microscope where lesions findings pertaining to platynosomosis were recorded.

\section{Molecular identification of adult fluke}

An adult fluke from each of 12 liver samples was used as a representative for molecular identification. DNA extraction of flukes was conducted by using commercially available extraction kits, DNEasy Blood, and Tissue Kit (Qiagen, Germany) according to the manufacturer's protocol. DNA was then eluted in $100 \mu \mathrm{L}$ of elution buffer and stored at $-20^{\circ} \mathrm{C}$ before PCR amplification. PCR was performed in a total volume of $25 \mu \mathrm{l}$ which consist of $10.4 \mu \mathrm{l}$ of sterile distilled water, $5 \mu$ l of $5 X$ Green GoTaq ${ }^{\circledR}$ Flexi Buffer (polymerase buffer), $5 \mu \mathrm{l} 2 \mathrm{mM}$ of Magnesium Chloride $\left(\mathrm{MgCl}_{2}\right)$ solution, $0.3 \mu \mathrm{l} 10 \mathrm{mM}$ dNTP Mix, $1 \mu \mathrm{l}$ of forward primer, $1 \mu \mathrm{l}$ of reverse primer and $0.3 \mu \mathrm{l}$ of GoTaq $^{\circledR}$ DNA Polymerase (Promega, USA) with cycling condition of at $94^{\circ} \mathrm{C}$ for $5 \mathrm{~min}, 30$ cycles at $94^{\circ} \mathrm{C}$ for $30 \mathrm{sec}, 53^{\circ} \mathrm{C}$ for $30 \mathrm{sec}$ and $72^{\circ} \mathrm{C}$ for 30 second followed by a final extension at $72^{\circ} \mathrm{C}$ for $7 \mathrm{~min}$. For confirmation of $P$. fastosum, PCR amplification was conducted targeting the 950bp fragment of the ITS1 gene using primers ITS5 (5'-GGAAGTAAAAGTCGTAACAAGG-3') and d58R (5'CACGAGCCGAGTGATCCACCGC-3') (Pinto et al., 2018). DNA amplifications were performed using $53^{\circ} \mathrm{C}$ melting temperature in a Thermal Cycler (Bio-Rad, MyCycler ${ }^{\circledR}$ USA). PCR products were purified and sequenced using the cycle sequencing technology (dideoxy chain termination/cycle sequencing) on ABI PRISM 3730xI Genetic Analyser (Applied Biosystems, USA). The sequences obtained were subjected to nucleotide BLAST identity search (NCBI).

\section{Statistical analysis}

All the data were recorded in a Microsoft Excel spreadsheet and transferred to the Statistical Package for Social Science (SPSS, Version 23) for analysis. The presence and absence of the adult flukes in the liver of euthanised cats were recorded and the number of flukes per animal was documented to calculate the fluke burden of each sample. For faecal samples from pet and shelter cats, the number of ova for each ova-positive sample were recorded. The presence of $P$. fastosum infections in stray, shelter and pet cats from Selangor and Kuala Lumpur was analysed using global prevalence to calculate expected frequencies with $95 \%$ confidence interval $(\mathrm{Cl})$. Correlation of $P$. fastosum infections in cats with the management of the shelters were analysed using Pearson correlation analysis. Fleiss Kappa test was performed to determine the agreement between the faecal examination. Furthermore, the parameters were estimated at $95 \%$ confidence intervals and a p-value of 0.05 or less $(p \leq 0.05)$ was considered to indicate a statistically significant difference. 
Table 1. Detection of Platynosomum fastosum from pet, shelter and stray cats through simple floatation and FE sedimentation methods

\begin{tabular}{lcccccc}
\hline & $\mathrm{N}$ & FE sedimentation & Simple & floatation & Both methods & Total positive sample \\
\hline Pet cats & 82 & 3 & 2 & 2 & 6 \\
Shelter cats & 119 & 3 & 1 & 1 & 0.49 \\
\hline
\end{tabular}

${ }^{*} \mathrm{~K}=$ Fleiss' kappa coefficient.

\section{RESULTS}

\section{Platynosomum fastosum detection in faecal samples}

A total of 201 faecal samples were obtained from eight shelters and five veterinary clinics. About $40.8 \%$ samples were from pet cats $(n=82)$ and $59.2 \%$ from shelters $(n=119)$. All cats involved were adults. The sex of cats from the shelters was undetermined due to the sampling in shared litterboxes. However, among 82 faecal samples of pet cats, 34 cats were female and 48 cats were male. Among 82 samples of pet cats, ova of $P$. fastosum were identified in three faecal samples from female cats $(3.66 \%, \mathrm{Cl}: 0.945$ $11.40)$, whereas $P$. fastosum ova were detected in three out of 119 faecal samples $(2.52 \%, \mathrm{Cl}: 0.65-7.74)$ obtained from the shelters. Two of the positive samples from the shelters were coming from the same shelter; however, the samples were obtained from different cages.

All samples were detected using two different faecal examination (Table 1). All positive samples were identified through centrifugal faecal sedimentation test in FE solution. The simple floatation technique could only detect three positive samples. Thus, if the centrifugal faecal sedimentation test in FE solution was not implemented in this study, three of the six positive samples would have been missed. Based on the Fleiss Kappa test, there was a moderate agreement $(\mathrm{K}=0.49,95 \% \mathrm{Cl}, 0.352$ to $0.628, \mathrm{p}<0.01)$ between formalin-ether sedimentation technique and simple floatation technique.

Association of management and behaviour of cats with parasite detection

Thirty complete responses from the cat owners were obtained for this study. Among the respondents for pet cats, five of them were representatives from veterinary clinics for resident cats.

The data of pet cats obtained from the questionnaire are shown in Table 2. The majority of the pet cats (83.3\%) were indoor cats. In this study, all positive samples from pet cats were indoor cats. However, through the questionnaire, two of the three positive cats were allowed to roam outdoor. Most cats involved (60\%) in this study hunt and prey for lizards and cockroaches.

Among eight shelters that involved in this study, seven of them practiced indoor housing (Table 3). However, $P$. fastosum ova were detected in two samples collected from Shelter 1 despite having indoor housing. Preying and hunting behaviour of cats is one of the important factors that determine $P$. fastosum infection. In this study, five of the shelters involved agreed that their cats demonstrate the behaviour of hunting and preying for lizards and cockroaches. All shelters practiced a scheduled deworming as a preventive measure against endoparasites. Almost half of the shelters claimed that pests were unable to access the feeding area. All respondents had no knowledge and awareness regarding platynosomiasis and the associated significant health effects. However, there is no significant association observed between the management practices in shelter and the $P$. fastosums infections (Table 4).

Table 2. Management practices and behaviour of pet cats obtained from the survey of 30 cat owners from March to September 2019

\begin{tabular}{lccc}
\hline Management Practices & \multicolumn{3}{c}{ Variables } \\
\hline Housing & Indoor & Outdoor \\
& 25 & 5 & \\
Hunting instinct & Yes & No & Maybe \\
& 18 & 7 & 5 \\
Feeding on geckos/ & Yes & No & Maybe \\
cockroaches & 1 & 24 & 5 \\
Access of pest to & Yes & No & \\
feeding area & 7 & 23 & \\
Antiparasitic drug & Yes & No & \\
& 29 & 1 & \\
\hline
\end{tabular}

Table 3. Management practices obtained from the survey of eight cat shelters

\begin{tabular}{|c|c|c|c|c|c|c|c|c|}
\hline $\begin{array}{l}\text { Shelter no/ } \\
\text { Management practices }\end{array}$ & 1 & 2 & 3 & 4 & 5 & 6 & 7 & 8 \\
\hline Housing & Indoor & Indoor & Indoor & Indoor & Indoor & Outdoor & Indoor & Indoor \\
\hline Hunting instinct & Yes & No & Yes & No & Yes & Yes & Yes & Maybe \\
\hline $\begin{array}{l}\text { Feeding on geckos / } \\
\text { cockroaches }\end{array}$ & Maybe & No & No & No & Maybe & Yes & Maybe & Maybe \\
\hline $\begin{array}{l}\text { Access of pest to } \\
\text { feeding area }\end{array}$ & No & Yes & Yes & No & No & Yes & No & No \\
\hline Antiparasitic drug & Yes & Yes & Yes & Yes & Yes & Yes & Yes & Yes \\
\hline P. fastosum discovery & Positive & Negative & Negative & Negative & Negative & Negative & Positive & Negative \\
\hline
\end{tabular}


Table 4. Pearson correlation coefficients $(r)$ and the significant value $(p)$ of the management practices in cat shelters to the P. fastosum infections

\begin{tabular}{lccccc}
\hline & Housing & $\begin{array}{c}\text { Hunting } \\
\text { instinct }\end{array}$ & $\begin{array}{c}\text { Feeding } \\
\text { geckoes }\end{array}$ & $\begin{array}{c}\text { Access of pest } \\
\text { to feeding area }\end{array}$ & $\begin{array}{c}\text { History of } \\
\text { clinical signs }\end{array}$ \\
\hline Correlation coefficient $(r)$ with the infections & 0.218 & 0.408 & -0.518 & -0.447 & -0.149 \\
Significant value $(p<0.05)$ & 0.604 & 0.315 & 0.188 & 0.267 & 0.725 \\
\hline
\end{tabular}

Table 5. The detection of Platynosomum fastosum in female and male stray cats by post-mortem examination

\begin{tabular}{|c|c|c|c|c|c|}
\hline & Number of cats & Number of fluke-positive cats & Detection (\%) & $\mathrm{Cl}$ & Chi-square \\
\hline \multicolumn{6}{|l|}{ Sex } \\
\hline Female & 26 & 9 & $34.62 \%$ & & $\chi^{2}=3.74, \mathrm{df}=1$ \\
\hline Male & 25 & 3 & $12 \%$ & & $p=0.05$ \\
\hline
\end{tabular}

\section{Platynosomum fastosum detection in post-mortemed cats}

Based on dental age estimation, all samples collected from the post-mortem examination were from adult cats $(\geq 1$-yearold). Twelve cats $(23.53 \%$; $95 \% \mathrm{Cl}: 10.8-37.2)$ comprising nine female $(34.6 \%)$ and three male cats $(12 \%)$ were positive for $P$. fastosum through the recovery of fluke in their liver samples. There was no significant difference in the $P$. fastosum detection and the gender of the animals (Table 5).

\section{Macroscopic and microscopic examination of liver}

The description in this section is based only on the positive cats since those that were negative showed normal morphology of body tissue. The most consistent gross lesion was mottling of the liver $(33.3 \%$, ) in four cats of the 12 positive samples (Figure 2A). The remaining samples (66.7\%) did not exhibit any gross lesions or abnormalities. However, all of the positive samples showed distention of the gall bladder filled with bile (Figure 2B). Eight cats (66.7\%) had thick tenacious olive-green bile, three had pervaded bile with dark brown discolouration (25.0\%), whereas thick yellowish bile was observed in the remaining samples (8.3\%). The adult flukes were commonly found in the intrahepatic biliary duct and gall bladder, nonetheless, one of the flukes was obtained from the small intestine from one of the samples. All positive cats which harboured adult flukes in the liver were also ova positive through bile examination. The fluke burden ranged from as low as 1 fluke to as high as 230 flukes per cat and nine of the cats $(75.0 \%)$ surpassed the high burden (> 125 flukes). Hepatic steatosis was noticed (22.2\%) in three fluke-positive cats (Figure $3 \mathrm{~A}$ ) and adult flukes were present in the distended biliary duct (Figure 3B). In all fluke-positive cats, biliary duct hyperplasia was evident (Figure 3C). Inflammation was demonstrated in four fluke-positive liver samples (33.3\%) with the presence of inflammatory cell infiltration, which was composed of eosinophils, lymphocytes and macrophages (Figure 3D).

\section{Species Identification}

The ova of $P$. fastosum observed in bile and faecal samples were brown in colour, possessed an operculum at one end of the ova with the size ranging from $24.33-33.87 \mu \mathrm{m}$ length and $39.56-46.92 \mu \mathrm{m}$ width (Figure $4 \mathrm{~A}, 4 \mathrm{C}$ ). The adult fluke was lanceolate and covered by thin cuticles with sizes ranging from 2.9 to $8 \mathrm{~mm}$ long and 0.9 to $2.5 \mathrm{~mm}$ wide (Figure $4 \mathrm{~B})$. It had a sub-terminal oral sucker and a ventral sucker about one quarter the body length from the anterior end. The liver fluke possessed a paired longitudinal testis on either side of the ventral sucker and the ovary was situated behind one of the testes; hence, it is considered a hermaphrodite (Soulsby, 1968; Vieira et al., 2009; Montserin et al., 2013).

All 12 sequences from flukes of $P$. fastosum ITS1 gene were obtained from the PCR (GenBank accession numbers MT015694- MT015705). Most of the sequences $(n=8)$ had a similarity of $99 \%$ with the P. illiciens sequence from Brazil (Pinto et al., 2018) while four sequences had a similarity of 99\% with $P$. fastosum sequences from Vietnam (Nguyen et al., 2017) in the NCBI GenBank.

\section{DISCUSSION}

The present study provides insight into the detection of $P$. fastosum among cats in Klang Valley, Malaysia using faecal techniques and post-mortem isolation of the parasite stages. The lesions associated with the affected organ in infected cats and their management were explained. Based on the faecal examination, the detection of $P$. fastosum in cats in Klang Valley, Malaysia was considered low in shelters and pet cats, which was $3.66 \%$ and $2.52 \%$, respectively as compared to detection in stray cats $(23.53 \%)$ by post-mortem examination. The low detection using faecal techniques corroborates the findings from studies conducted in other countries. For instance, in Brazil, the detection of $P$. fastosum ranged from $0.47 \%-30 \%$ using either water-ether, zinc sulphate, formalin-ether, sucrose centrifugation floatation and simple or sucrose sedimentation centrifugation techniques (Rocha et al., 2014; Ramos et al., 2016). Likewise, a study in Bangkok reported a prevalence of $0.07 \%(n=1 / 1485)$ $P$. fastosum in faecal samples from stray cats using formalin ethyl-acetate centrifugal sedimentation (Jittapalapong et al., 2007), whereas a higher prevalence of $81 \%(n=81 / 100)$ was found in West Indies using a modified double-centrifugation and bench-top floatation techniques (Krecek et al., 2010). These findings revealed that the prevalence rate may varies depending on the employed faecal techniques. A recent study suggested that the use of the FLOTAC technique (Ramos et al., 2016) and double centrifugation with Sheather's sugar floatation technique (Eisenbraun et al., 2020) are the most effective techniques in detecting $P$. fastosum infaecal samples. From the current work, the formalin-ether 


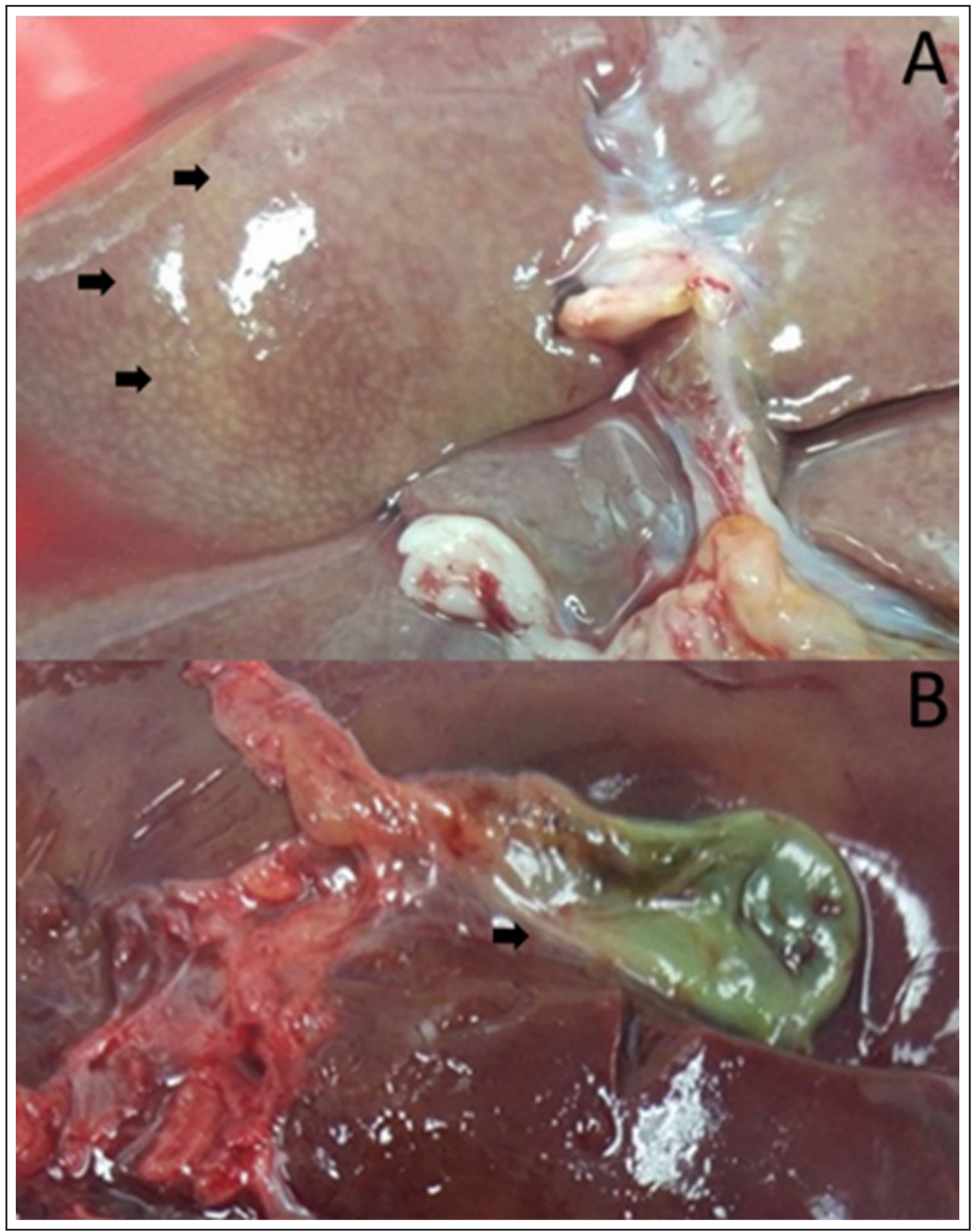

Figure 2. Gross lesion of the liver samples from Platynosomum fastosum infected cats. (A) Liver mottling of $P$. fastosum positive sample (B) Previously distended gall bladder with aspirated bile fluid. 


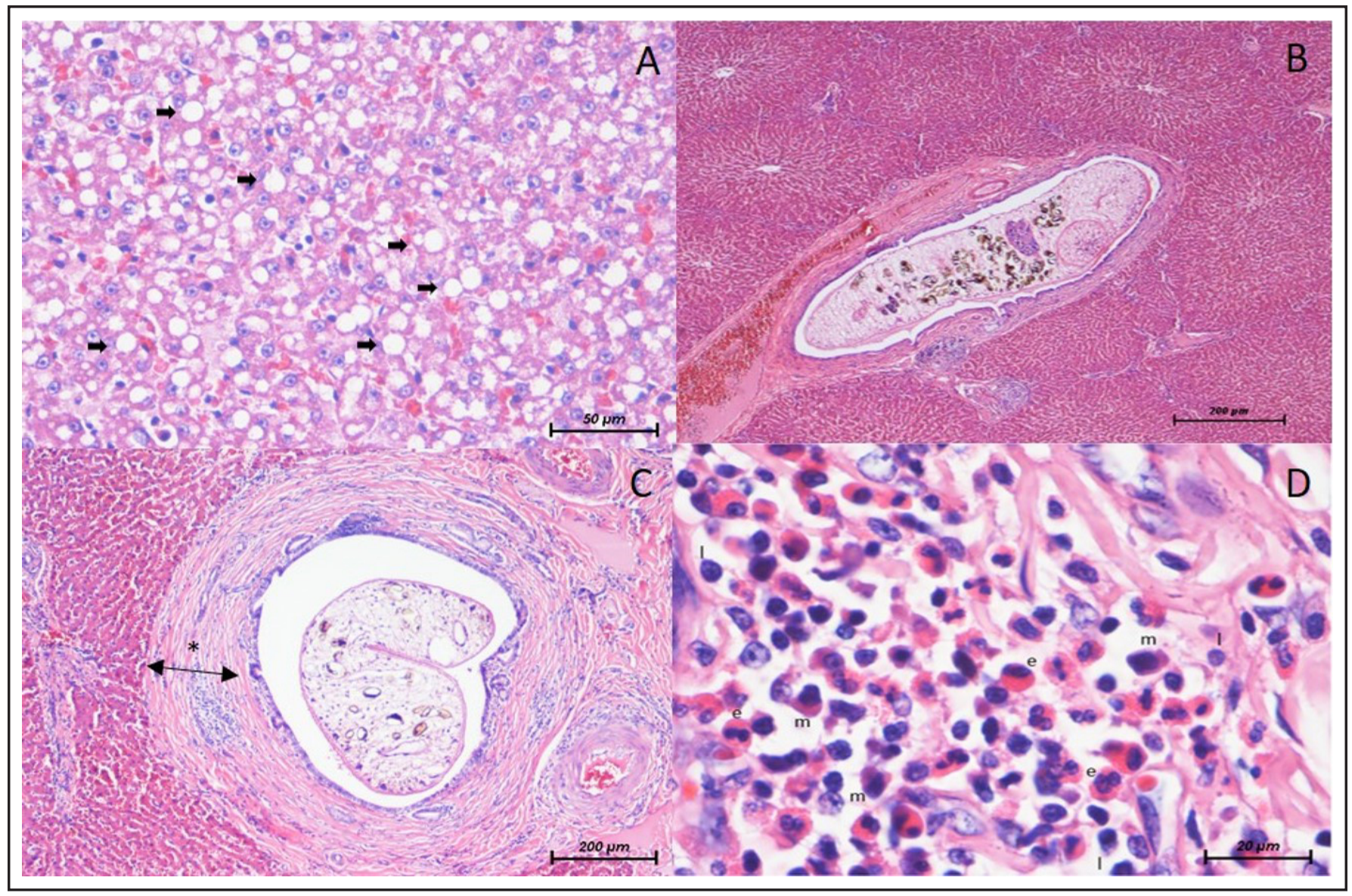

Figure 3. Histopathology examination of the liver of infected samples. (A) Hepatic steatosis of liver tissue (H\&E stain) (arrow) (B) Presence of adult fluke in distended biliary duct (C). Hyperplasia of biliary epithelium with periductal fibrosis (asterisk) and intraductal presence of adult fluke (H\&E stain). (D) Inflammatory cell infiltration in the liver sample (H\&E stain) (e = eosinophil, $\mathrm{m}=$ macrophage, $\mathrm{I}=$ lymphocyte).

centrifugal sedimentation technique was similar to the simple floatation technique in detecting positive samples according to Fleiss Kappa test. Simple floatation technique is the most common technique used in detecting parasitic infection in cats in veterinary clinics or laboratories in Malaysia. However, the use of formalin-ether centrifugal sedimentation technique was believed to be a better method in contrast to other faecal examination like direct smear, sugar flotation, zinc sulfate flotation, or detergent sedimentation techniques (Palumbo et al., 1976).

Various faecal detection techniques have been published worldwide for the detection of Platynosomum sp. infection. However, there is also variation in their effectiveness to detect the fluke ova in the faeces. Furthermore, bile duct obstruction might develop during the course of the disease as part of either mechanical or inflammatory processes due to the presence of the parasite in the bile duct (Lima et al., 2008). As a result of the obstruction, the fluke ova present in the bile duct are unable to be passed into the faeces through the intestinal tract, thus making them undetectable. In addition, the identification of fluke ova in faecal samples could be challenging due to the appearance of small size and immature ova having different morphology compared to those described in previous studies (Palumbo et al., 1976; Ferreira et al., 1999). To the best of the researcher's knowledge and based on the available literature, there is no 'gold standard' test for the detection of $P$. fastosum infection in the faeces of cats (Ramos et al., 2016).
Most of the studies conducted in Malaysia on the detection of $P$. fastosum in cats were based on post-mortem examination of stray cats with the prevalence ranging from 9.8\% to 73\% (Zamri-Saad et al., 1984; Amin-Babjee, 1978; Mohd Zain et al., 2013; Retnasabapathy \& Prathap, 1971). The higher detection of $P$. fastosum in the hepatobiliary system of cats as compared to the detection in faecal samples agrees with other studies conducted in Brazil with detection ranges of $0.9-40.0 \%$ (Ramos et al., 2016), $15.0-41.0 \%$ in Hawaii (Ash, 1962; Palumbo et al., 1974), 81.0\% in the Bahamas (Leam \& Walker, 1963), $81.0 \%$ in St. Kitts (Krecek et al., 2010) and 14.6\% in Cayman Island (Headley et al., 2012). An earlier study on $P$. fastosum reported a detection rate of $73.0 \%$ (222/304) by postmortem examination and only $25.3 \%$ were positive $(n=77)$ through faecal analysis from the same samples. Thus, 145 positive samples remained unnoticed if only faecal techniques were used in the diagnosis (Retnasabapathy \& Prathap, 1971). This proved that faecal examination alone is not robust enough to detect the infection. Previous work suggested the use of fine-needle aspiration (FNA) as the most reliable test in diagnosing $P$. fastosum infections in cats. However, this method requires high levels of expertise and might induce bile peritonitis in cats following the FNA procedure (Ikhwan-Saufi et al., 2020). The cat owners will most likely reject this method due to its invasive nature and the risk associated with anaesthesia when performing the procedure.

In this study, the detection of cat liver fluke in pet pets was generally lower than the free-roaming and shelter cats. 


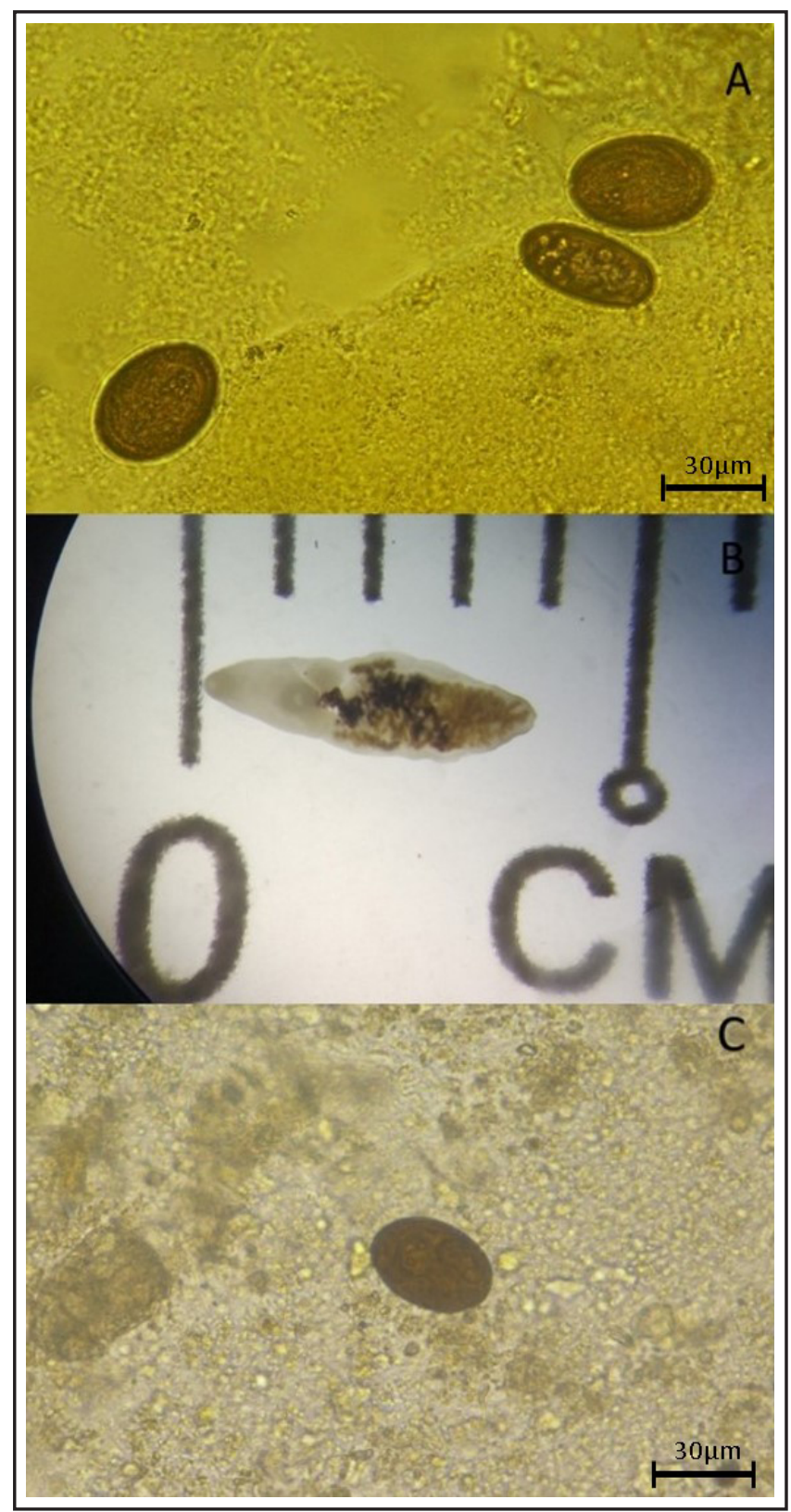

Figure 4. Stages of Platynosomum fastosum observed in the study. (A) Ova of $P$. fastosum that was found in the bile of infected cat. (B) Adult $P$. fastosum discovered in gall bladder. (C) Ova of $P$. fastosum discovered in faecal samples of infected cats.

The chances of getting infected would be greatly reduced with routine veterinary care, restricted access to the outdoor environment and regular consumption of commercially prepared cat food (Nagamori, 2020). Presently, more cats are owned and homed under a much more hygienic condition and proper nutrition. Thus, the possibility of these owned and homed cats encountering lizards are much less. The awareness of parasite control together with increased availability of veterinary care in Malaysia might have led to better control of parasitic infections, including $P$. fastosum in cats.

From the questionnaire, all respondents had limited knowledge and awareness of platynosomiasis. There is data paucity on $P$. fastosum in Malaysia and it is often missed and undiagnosed by veterinarians when cats with liver problems are presented in clinics. These events might contribute to veterinarian low awareness of the significant health effects of $P$. fastosum in cats. Based on personal communication (Nor Azlina Abdul Aziz, personal communication) with several veterinary practitioners, platynosomiasis is often ruled out as one of the differential diagnoses even when the cat shows clinical signs like jaundice, anorexia and fever. Therefore, this shows that $P$. fastosum are often neglected considering the fatal effects it could cause to the infected cats.

In this study, most owners and shelters that practicing indoor housing also observed the presence of preying or hunting behaviour in their cats. However, there was no significant correlation between the management practices and hunting behaviour with the $P$. fastosum infection. Most sensible explanation is due to the low positive detection of $P$. fastosum which reduce the chances of capturing the association in the statistical analysis and could underestimate the real situation. In general, outdoor cats are at a higher risk of contracting parasitic infections as they are accessible to possible intermediate, paratenic and definitive hosts; thereby, increasing the chances of transmitting the parasite. However, in the case of platynosomiasis, both indoor and outdoor cats are at risk since the infective stages of $P$. fastosum. are present in the house geckos, as well as in cockroaches, and woodlice where both animals are easily available indoor and outdoor. Due to their preying behaviour, cats might be exposed to the intermediate/paratenic host of $P$. fastosum, house geckos, which plays an important role in the life cycle of the parasite (Hazreen, 2017; Pinto et al., 2017). Besides, the paratenic (house lizard) and intermediate (cockroaches and woodlice) hosts of $P$. fastosum are the common pests in Malaysian household. Overall, parasitic infections remain a vital challenge in the veterinary field, both to the health and welfare of companion animals. The complexity in controlling most parasites is linked to the involvement of a wide range of organisms as intermediate, paratenic and definitive hosts in their life cycles (Elsheikha, 2014).

The blast results showed the similarity of our $P$. fastosum isolate with $P$. fastosum in Vietnam and $P$. illiciens from Brazil. In general, there is scarce information on the molecular characterisation of $P$. fastosum in the literature and limited sequences available in the GenBank. The only available sequence is the partial region of rDNA, which is the ITS1 and 5.8 s region of $P$. fastosum from Vietnam (Nguyen et al., 2017) and ITS1 and cox1 sequence of $P$. illiciens from Brazil (Pinto et al., 2018). High similarities of sequences between P. illiciens and $P$. fastosum were highlighted in a recently published study, which suggests the similarity between both species (Pinto et al., 2018). In order to evaluate the molecular properties of $P$. fastosum isolate in our study to the previous works, further molecular works and analyses are required for a better understanding on this area

\section{CONCLUSION}

The detection of $P$. fastosum in in pet and shelter cats were considered low while a significant number of infections were observed in stray cats by post-mortem technique. Given the dense population of strays as well as pet cats in these urban areas, the detection of $P$. fastosum obtained is considered vital. The findings provide a better understanding of $P$. fastosum in cats in Klang Valley, Malaysia, thus providing insights for future research on $P$. fastosum. The information obtained from this study will highlight the importance of this parasite infections to the veterinarian. Further investigation on the epidemiology of this parasite, the risk of transmission and molecular characterisation is crucial information to be explored by researchers. 


\section{ACKNOWLEDGEMENTS}

We are grateful to the staff of city municipal for their help during samples collection, $\mathrm{Dr}$ Nazirah Abdullatad and her staffs from Petunia Animal Clinic who helped in post mortem and sample collection, Dr Farina Mustaffa Kamal who helped in euthanization of stray cats, Prof. Noordin Mohamed Mustapha for his valuable opinion in preparing the manuscript, Histopathology Laboratory, Faculty of Veterinary Medicine, UPM for the preparation of histology slides, Postgraduate students and Parasitology Laboratory's staffs for their kind assistance.

\section{Conflict of interest}

All authors have no conflict of interest concerning the work reported in this paper.

\section{REFERENCES}

Amin-Babjee, S.M. (1978). Parasites of the domestic cat in Selangor. Kajian Veterinar 10: 107-114.

Andrade, R.L.F.S., Dantas, A.F.M., Pimentel, L.A., Galiza, G.J.N., Carvalho, F.K.L., Costa, V.M.M. \& Riet-Correa, F. (2012). Platynosomum fastosum-induced cholangiocarcinomas in cats. Veterinary Parasitology 190: 277-280. https://doi.org/ 10.1016/j.vetpar.2012.04.015

Ash, L.R. (1962). Helminth parasites of dogs and cats in Hawaii. Journal of Parasitology 48: 63-65. https://doi.org/ $10.2307 / 3275412$

Basu, A.K. \& Charles, R.A. (2014). A review of the cat liver fluke Platynosomum fastosum Kossack, 1910 (Trematoda: Dicrocoeliidae). Veterinary Parasitology 200: 1-7. https:// doi.org/10.1016/j.vetpar.2013.12.016

Braga, R.R., Teixeira, A.C., Oliveira, J.A.A. \& Cavalcanti, L.P.G. (2016). Prevalence of Platynosomum fastosum infection in free roaming cats in northeastern Brazil: Fluke burden and grading of lesions. Veterinary Parasitology 227: 20-25. https://doi.org/10.1016/j.vetpar.2016.07.021

Bray, R.A., Gibson, D.I. \& Jones, A. (2008). Keys to the Trematoda, Volume 3. CABI Publishing, Wallingford, UK and the Natural History Museum, London, pp. 824. https://doi.org/10.1079/9780851995885.0000

Burkholder, W.J. (2000). Use of body condition scores in clinical assessment of the provision of optimal nutrition. Journal of American Veterinary Medicine Association 217: 650654. https://doi.org/10.2460/javma.2000.217.65

Carreira, V.S., Vieira, R.F., Machado, G.F. \& Luvizotto, M.C. (2008). Feline cholangitis/cholangiohepatitis complex secondary to Platynosomum fastosum infection in a cat. Revista Brasileira de Parasitologia Veterinária 17: 184-187.

Center, S.A. (1996). Diseases of the gallbladder and biliary tree. In: Small Animal Gastroenterology. 3rd edition. Philadelphia: WB Saunders, pp.860-888.

Daniel, A.G.T., Diaz, R.F., Camignatto, L.O., Kage, N.K., Pellegrino, A. \& Cogliati, B. (2012). Polycystic liver disease associated with Platynosomum fastosum infection in a cat. Brazilian Journal of Veterinary Pathology 5: 137-141

Day, D.G. (1995). Feline cholangiohepatitis complex. Veterinary Clinics of North America: Small Animal Practice 25: 375-385. https://doi.org/10.1016/s0195-5616(95)50032-4

Eisenbraun, H., Alluwie, A., Connolly, S., Nair, R., Verocai, G.G. \& Ketzis, J.K. (2020). Comparison of fecal analysis methods for the detection of Platynosomum fastosum in naturally infected cats. Journal of Feline Medicine and Surgery 22: 395398. https://doi.org/10.1177\%2F1098612X19848173

Elsheikha, H. 2014. Parasites in cats and dogs: Management and treatment. Veterinary Times 44: 8-11
Ferreira, A.M.R., Paes-de-Almeida, E.C. \& Labarthe, N.V. (1999). Liver fluke infection (Platynosomum concinnum) in Brazilian cats: prevalence and pathology. Feline Practitioner 27: 1922.

Hazreen, A.J. (2017). Dissertation: Community structure and infection characteristics of metazoan parasites in house Geckos in Peninsular Malaysia. Universiti Malaya.

Headley, S.A., Gillen, M.A., Sanches, A.W.D. \& Satti, M.Z. (2012). Platynosomum fastosum-induced chronic intrahepatic cholangitis and Spirometra spp. infections in feral cats from Grand Cayman. Journal of Helminthology 86: 209-214. https://doi.org/10.1017/S0022149X11000265

Ikhwan-Saufi, A.A., Ahmad-Rasul, R., Liew, H.X., Lim, M.Y., Adeline, T., Nuhanim, R., Daarulmuqaah, M., Amlizawaty, A., Maizatul-Akmal, M., Johaimi, J. et al. (2020). Clinical pathological findings of a cat with chronic cholangitis. Comparative Clinical Pathology 29: 17-23. https://doi.org/ 10.1007/s00580-019-03062-2

Jittapalapong, S., Inparnkaew, T., Pinyopanuwat, N., Kengradomkij, C., Sangvaranond, A. \& Wongnakphet, S. (2007). Gastrointestinal parasites of stray cats in Bangkok metropolitan areas, Thailand. Agriculture and Natural Resources 41: 69-73.

Kim, J.M., Che, J.H., Jeong, D.H. \& Kang, B.C. (2010). Platynosomum fastosum infestation in a domestic cat in Korea. Laboratory Animal Research 26: 307-309. https://doi.org/10.5625/ lar.2010.26.3.307

Krecek, R.C., Moura, L., Lucas, H. \& Kelly, P. (2010). Parasites of stray cats (Felis domesticus L., 1758) on St. Kitts, West Indies. Veterinary Parasitology 172: 147-149. https://doi.org/ 10.1016/j.vetpar.2010.04.033

Le, H.K. (2012) New findings on the cat liver flukes in some southern provinces of Vietnam. Journal of Veterinary Science and Technology 19: 14-18. (in Vietnamese)

Leam, G. \& Walker, I.E. (1963). The occurrence of Platynosomum fastosum in domestic cats in the Bahamas. Veterinary Record 75: 46-47.

Lima, G.S., Dabus, D.M.M., Trentin, T.D.C. \& Neves, M.F. (2008). Platynosomum fastosum. Revista Científica Eletrônica de Medicina Veterinária 11: 1-6. (in Portuguese)

Lima, R.L., de Campos Pacheco, R., Mendonça, A.J., Néspoli, P.E.B., Morita, L.H.M. \& Sousa, V.R.F. (2021). Platynosomum fastosum in domestic cats in Cuiabá, Midwest region of Brazil. Veterinary Parasitology: Regional Studies and Reports 24: 100582. https://doi.org/10.1016/j.vprsr.2021.100582

Mohd Zain, S.N.M., Sahimin, N., Pal, P. \& Lewis, J.W. (2013). Macroparasite communities in stray cat populations from urban cities in Peninsular Malaysia. Veterinary Parasitology 196: 469-477. https://doi.org/10.1016/j.vetpar.2013.03.030

Montserin, S.A.S., Munoz, K., Seebaransingh, R. \& Basu, A.K. (2013). Clinical case: Platynosomum fastosum Kossack, 1910 infection in a cat: first reported case in Trinidad and Tobago. Revue de Médecine Vétérinaire (Toulouse) 164: 9-12.

Nagamori, Y., Payton, M.E., Looper, E., Apple, H. \& Johnson, E.M. (2020). Retrospective survey of parasitism identified in feces of client-owned cats in North America from 2007 through 2018. Veterinary Parasitology 277: 109008. https:// doi.org/10.1016/j.vetpar.2019.109008

Nguyen, H.M., Van Hoang, H. \& Ho, L.T. (2017). Platynosomum fastosum (Trematoda: Dicrocoeliidae) from cats in Vietnam: morphological redescription and molecular phylogenetics. Korean Journal of Parasitology 55: 39. https://doi.org/10.3347\%2Fkjp.2017.55.1.39

Palumbo, N.E., Perri, S.F., Loo, B., Taylor, D. \& Reece, V. (1974). Cat liver fluke, Platynosomum concinnum, in Hawaii. American Journal Veterinary Research 35: 1455-1455. 
Palumbo, N.E., Taylor, D. \& Perri, S.F. (1976). Evaluation of fecal technics for the diagnosis of cat liver fluke infection. Laboratory Animal Sciences 26: 490-493.

Pinto, H.A., Mati, V.L. \& de Melo, A.L. (2014). New insights into the life cycle of Platynosomum (Trematoda: Dicrocoeliidae). Parasitology Research 113: 2701-2707. https://doi.org/10.1007/s00436-014-3926-5

Pinto, H.A., Pulido-Murillo, E.A., Braga, R.R., Mati, V.L., Melo, A.L. \& Tkach, V.V. (2018). DNA sequences confirm low specificity to definitive host and wide distribution of the cat pathogen Platynosomum illiciens (= P. fastosum) (Trematoda: Dicrocoeliidae). Parasitology Research 117: 1975-1978. https://doi.org/10.1007/s00436-018-5866-y

Pinto, H.A., Mati, V.L., Pujoni, D.G. \& Melo, A.L. (2017). Platynosomum illiciens (Trematoda: Dicrocoeliidae) in captive black-tufted marmoset Callithrix penicillata (Primates: Cebidae) from Brazil: a morphometric analysis with taxonomic comments on species of Platynosomum from nonhuman primates. Journal of Parasitology 103: 1421. https://doi.org/10.1645/16-1

Ramos, R.A.N., Lima, V.F.S., Monteiro, M.F.M., de Andrade Santana, M., Lepold, R., da Gloria Faustino, M.A., Rinaldi, L., Cringoli, G. \& Alves, L.C. (2016). New insights into diagnosis of Platynosomum fastosum (Trematoda: Dicrocoeliidae) in cats. Parasitology Research 115: 479-482. https://doi.org/10.1007/s00436-015-4763-x

Ramos, D.G.D.S., Santos, A.R.G.L.O., Freitas, L.D.C., Braga, Í.A., Silva, E.P.D., Soares, L.M.C., Antoniassi, N.A.B., Furlan, F.H. \& Pacheco, R.D.C. (2017). Feline platynosomiasis: analysis of the association of infection levels with pathological and biochemical findings. Revista Brasileira de Parasitologia Veterinária 26: 54-59. https://doi.org/10.1590/S198429612017009

Retnasabapathy, A. \& Prathap, K. (1971). The liver-fluke Platynosomum fastosum in domestic cats. Veterinary Record 88: $62-65$.

Rocha, N.O., Portela, R.W., Camargo, S.S., Souza, W.R., Carvalho, G.C. \& Bahiense, T.C. (2014). Comparison of two coproparasitological techniques for the detection of Platynosomum sp. infection in cats. Veterinary Parasitology 204: 392-395. https://doi.org/10.1016/j.vetpar.2014.04.022

Rodriguez-Vivas, R.I., Williams, J.J., Quijano-Novelo, A.G., Bolio, G.M.E. \& Torres-Acosta, J.F.J. (2004). Prevalence, abundance and risk factors of liver fluke (Platynosomum concinnum) infection in cats in Mexico. Veterinary Record 154: 693-694. https://doi.org/10.1136/vr.154.22.693
Salomao, M., Souza-Dantas, L.M., Mendes-de-Almeida, F., Branco, A.S., Bastos, O.P.M., Sterman, F. \& Labarthe, N. (2005). Ultrasonography in hepatobiliary evaluation of domestic cats (Felis catus, L., 1758) infected by Platynosomum Looss, 1907. The International Journal of Applied Research in Veterinary Medicine 3: 271-279.

Shanta, C.S., Wan, S.P. \& Kwong, K.H. (1980). A survey of the endo-and ectoparasites of cats in and around Ipoh, West Malaysia. Malaysian Veterinary Journal 7: 17-27.

Soulsby, E.J.L. (1968). Helminths, arthropods and protozoa of domesticated animals. 7th edition. Philadelphia: Lee \& Febiger, pp. 26-27.

Sutton, L.K., Byrd, J.H. \& Brooks, J.W. (2018). Age determination in dogs and cats. In: Veterinary Forensic Pathology, Volume 2. Cham: Springer, pp. 151-163.

Soto, J.A., Villalobos, A., Arraga de Alvarado, C.M. \& Chirinos, A.R. (1991). Obstructive biliary cirrhosis in a cat due to Platynosomum fastosum infection. Revista Cientifica FCV de LUZ 1: 16-19.

Taylor, D. \& Perri, S.F. (1977). Experimental infection of cats with the liver fluke Platynosomum concinnum. American Journal of Veterinary Research 38: 51-54.

Underwood, W. \& Anthony, R. (2020). AVMA guidelines for the euthanasia of animals: 2020 edition. https://www. avma.org/sites/default/files/2020-01/2020-EuthanasiaFinal-1-17-20.pdf. Accessed 31 March 2021.

Vieira, A.L., Ecco, R., Lima, W.S. \& Guedes, R.M. (2009). Platynosomum fastosum infection in two cats in Belo Horizonte, Minas Gerais State. Brazilian Journal of Veterinary Pathology 2: 45-48.

Warren, K.S., Swan, R.A., Hobbs, R.P., Kuhn, E.M. \& Heeney, J.L. (1998). Platynosomum fastosum in ex-captive orangutans from Indonesia. Journal Wildlife Disease 34: 644-646. https://doi.org/10.7589/0090-3558-34.3.644

Xavier, F.G., Morato, G.S., Righi, D.A., Maiorka, P.C. \& Spinosa, H.S. (2007). Cystic liver disease related to high Platynosomum fastosum infection in a domestic cat. Journal Feline Medicine Surgery 9: 51-55. https://doi.org/10.1016\%2Fj.jfms.2006. 08.006

Zajac, A.M. \& Conboy, G.A. (2006). Veterinary Clinical Parasitology. 7th edition. lowa: Blackwell Publishing, pp. 259261.

Zamri-Saad, M., Chulan, U. \& Wong, W.T. (1984). Platynosomum fastosum infestation in a cat: a case report. Pertanika 7: 87-89. 